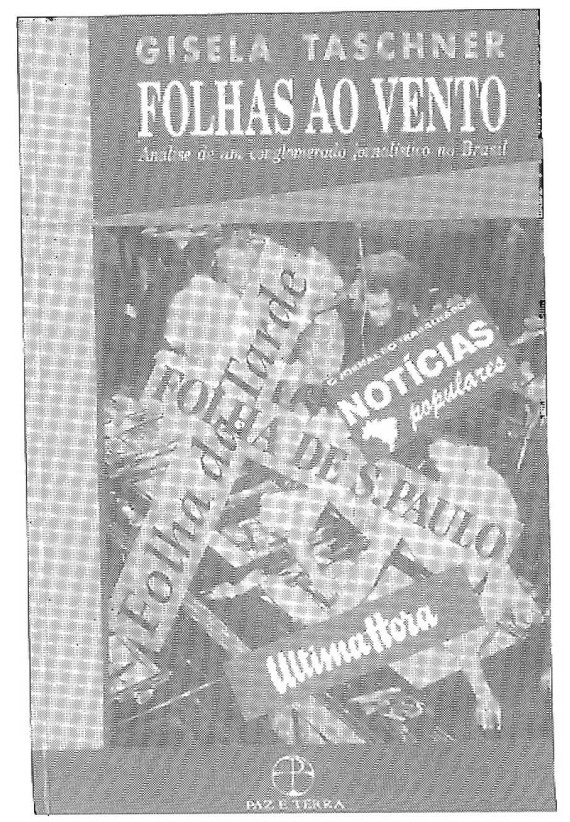

\section{FOLHAS AO VENTO: ANÁLISE DE UM CONGLOMERADO IORNALISTICO NO BRASIL}

\section{de GISELA TASCHNER}

Rio de Janeiro: Paz e Terra, 1992, 230 p.

Por Maria Luisa Nabinger de Almeida, Doutora em Ciência Política pela USP, Professora do Departamento de Fundamentos Sociais e Jurídicos da EAESP/FGV.

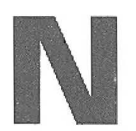
o final do ano passado, enquanto O Estado de São Paulo publicava os números sobre os candidatos inscritos na primeira fase do vestibular da FUVEST/92 para o curso de jornalismo da Universidade de São Paulo - 2.007 candidatos representavam $46,1 \%$ de inscritos para cada uma das 45 vagas oferecidas pela Escola de Comunicação e Artes - ECA, a Editora Paz e Terra lançava no mercado editorial o livro da Profa. Gisela Taschner - Folhas ao Vento: análise de um conglomerado jornalístico no Brasil.

A quase simultaneidade desses dois acontecimentos revelou uma convergência paradoxal: por um lado, jovens vestibulandos atraídos pelo prestígio alcançado pela imprensa ao desvendar, pelo avesso, o "Estado moderno" levado a cabo pelo governo Collor; e, por outro, um estudo, resultante de uma tese de doutoramento em Sociologia na USP, desmitificando as relações sociais criadas na imprensa com a constituição da indústria no Brasil contemporâneo.

O trabalho empreendido pela autora mostrou ser a
Sociologia uma "Ciência de relaçōes" por excelência: além de abordar o desenvolvimento de uma lógica empresarial e as inovações no processo de trabalho do setor jornalístico, o livro indicou, ainda, as transformações do processo produtivo da informação em consonância com o processo de acumulação, desde o periodo liberal até a fase do capitalismo monopolista tardio.

$O$ estudo de caso, que abrange a formação do grupo FOLHAS, traduziu, assim, a ambivalência da indústria cultural: a imprensa, uma vez integrada, pouco a pouco, aos elementos próprios de uma empresa moderna, torna-se um produto com valor de troca, ou seja, uma mercadoria.

Folhas ao Vento se estruturou de acordo com essa lógica. De início, a imprensa se expressou enquanto uma "mercadoria envergonhada", cuja "missão" não visava ao lucro: "As práticas mercantis não tinham sido totalmente sancionadas de um ponto de vista ético, e menos ainda quando referentes à mercantilização do trabalho intelectzial." (p. 37).

$\mathrm{Da}$ "Empresa Emergente", o grupo FOLHAS atinge a fase da "Empresa Explícita" (I e II Partes), consolidando tanto a empresa (sujeito) com a construção das bases físicas e empresariais, quanto o produto: a informação (objeto). Doravante, o mecanismo de "concentrar para diversificar" se expressou não só através do aumento do número de páginas, como ainda implicou na diversificação dos produtos: além da Folha da Noite e Folha da Manhã, foi criada a Folha da Tarde. O resultado dessas modificações editoriais consistiu, posteriormente, na criação de Cadernos - "Assuntos diversos", Economia e finanças, Esportes, Crônica Social, "Atualidades e Comentários", "Mulher e Lar", desbravando o caminho para a chamada "imprensa de massa".

Até aqui, não é exagero aproximar o desenvolvimento do setor jornalístico com as características do putting out system e do factory system, experimentado pelos demais setores produtivos. Aliás, a autora, ao buscar a caracterização da atividade jornalística como um trabalho produtivo, do ponto de vista marxista, alcançou o cerne da evolução histórica do setor e, em particular, do grupo FOLHAS. Assim, tanto a publicidade quanto os setores automobilístico, financeiro e outros, na qualidade de anunciantes, promoveram a consolidação da indústria cultural, cuja alavanca principal se concentrou no próprio Estado burocrático-autoritário.

A "Empresa Rainha" e "O Conglomerado"(III e IV Partes), expressaram, por conseguinte, outro estágio do "binômio centralização-diversificação: o grupo FOLHAS não só recompôs o processo produtivo-produção e reprodução da mensagem, distriburição, vendas, publicidade, administração e serviços de apoio -, cono também diversificou os produtos com vistas ao segmento de mercado. Essa estratégia, que objetivou o 
crescimento interno e externo do grupo, é o indicador de uma lógica orgânica empreendida pela gerência moderna.

Uma palavra a mais: foi intencional a menção que fizemos, inicialmente, a noticia divulgada por um dos jomais do grupo ESTADO. Na origem, os atuais concorrentes estiveram imbricados. O primeiro número, por exemplo, do jornal Fotha da Noite circulou com um editorial assinado por Júlio de Mesquita Filho. A perspectiva, aparentemente, "oportunista" da matéria "Nosso programa", como assinalou a autora, nada mais foi que uma manifestação sintomática do deslanchar, décadas mais tarde, de uma imprensa de indústria cultural, cuja "mensagem-mercadoria serve à lógica $e$ aos espaços do mercado e nẫo ntecessariamente às opiniões do dono do jornal" (p. 41-42). Ademais, a impessoalidade resultante também para os jornalistas-trabalhadores na produção da informação, permitiu-nos alcançar os destinatários de Folhas ao Vento: trata-se não só de jovens estudantes sequiosos de uma duvidosa fama na área de comunicação, como ainda de futuros administradores que, lentamente, percebem um novo campo de trabalho. Afinal, não há mais nenhuma incompatibilidade entre o exercício de administrar e o de produzir a notícia nos conglomerados jornalísticos.

Folhas ao Vento supera, por fim, na área da Sociologia do Trabalho, a escassez da temática sobre o processo de trabalho na produção da informação, cuja lacuna, como núcleo orientador tanto para os estudos quanto para as pesquisas no meio acadêmico, justificou, outrora, a mítica do setor jomalístico.

\section{O TRABALHO CRIATIVO - O PAPEL CONSTRUTIVO DOS NEGÓCIOS NUMA SOCIEDADE EM TRANSFORMAÇÃO}

de W. HARMAN E J. HORMANN

Săo Paulo: Cultrix, 1990.

Por Maria Ester de Freitas, Protessora Assistente do Departamento de Administração Geral e Recursos Humanos da EAESP/FGV.

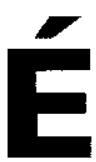

sempre mais que saudável a realização e divul gação de pesquisas que se preocupem em analisar, a partir de uma perspectiva global, a natureza das mudanças que estamos vivendo. Nos últímos anos, em especial, a produção científica sobre essas questões tem se intensificado de forma significativa e

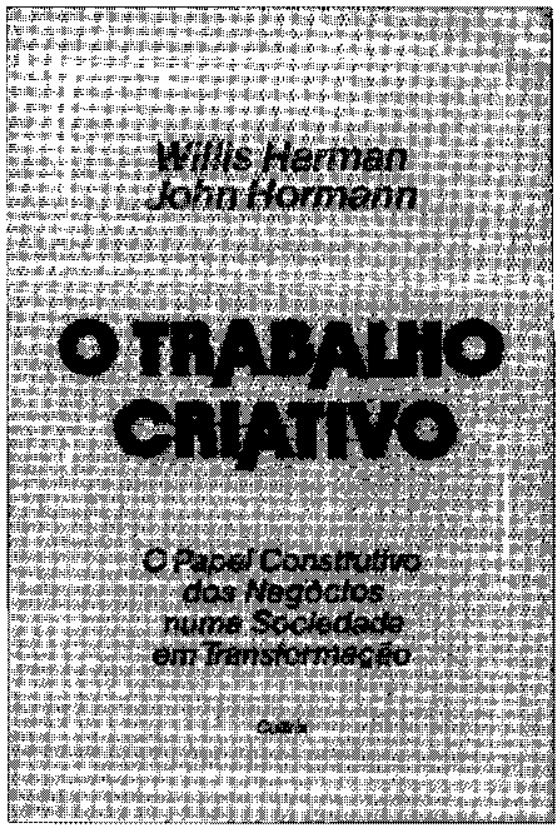

vemos esse fato como uma indicação de que o destino, da sociedade moderna - em particular, a Ocidental se apresenta de maneira problemática.

Livros como O Choque do Futuro, A Terceira Onda, Megatendências, Megatendéncias 2000, certamente buscaram um mapeamento da situação atual do mundo capitalista moderno e procuraram analisar possiveis alternativas para essa sociedade. Recortes de uma realidade complexa e multifacetada, essa produção acadêmica, em alguns casos, tem se alternado em visôes otimistas, pessimistas, ingênuas ou românticas. A tecnologia é vista ora como um elemento libertador, ora como um novo tipo de tirano que submete a todos silenciosamente.

O trabalho de Harman e Hormann opta por uma visão otimista, porém o cenário atual é traçado de forma realista e responsável, o que significa ser deprimente em alguns momentos. Possivelmente é esta a maior contribuiçăo dos autores, ou seja, apresentar de maneira crua os problemas que devem ser enfrentados não por uma nação específica, mas por todo os que habitam o planeta Terra.

Seria, sem duvida, uma grande ingenuidade apostarmos na hipótese de uma grande comunidade terrestre, que comungaria do mesmo esforço no sentido de salvar o planeta e que teria a responsabilidade de construir um futuro limpo, justo e perfeito para as próximas geraçôes.

Não, nada tão cor-de rosa! $\mathrm{A}$ partir de uma ampla bibliografia os pesquisadores se propóem a analisar aspectos relacionados ao mundo do trabalho, as origens dos dilemas modernos, o embrião de um novo tecido social, as características da sociedade emergente, e, por fim, o papel que cabe aos negócios para o encaminhamento de soluçốes para essas questões. 